\title{
Intraperitoneal Chemotherapy for Gastric Cancer with Peritoneal Carcinomatosis: Is HIPEC the Only Answer?
}

\author{
Ka-On Lam ${ }^{1}$, Betty Tsz-Ting Law ${ }^{2}$, Simon Ying-Kit Law ${ }^{2}$, Dora Lai-Wan Kwong1 \\ ${ }^{1}$ Department of Clinical Oncology, LKS Faculty of Medicine, The University of Hong Kong, Hong Kong, China \\ ${ }^{2}$ Department of Surgery, LKS Faculty of Medicine, The University of Hong Kong, Hong Kong, China \\ Email: ${ }^{*}$ lamkaon@hku.hk
}

Received 13 January 2014; revised 16 February 2014; accepted 26 February 2014

Academic Editor: Stephen L. Chan, The Chinese University of Hong Kong, Hong Kong, China

Copyright (C) 2014 by authors and Scientific Research Publishing Inc.

This work is licensed under the Creative Commons Attribution International License (CC BY).

http://creativecommons.org/licenses/by/4.0/

(c) (i) Open Access

\begin{abstract}
Gastric cancer with peritoneal carcinomatosis is notorious for its dismal prognosis. While the pathophysiology of peritoneal dissemination is still controversial, the rapid downhill course is universal. Patients usually suffer abdominal distension, intestinal obstruction and various complications before they succumb after a median of 3 - 6 months. Although not adopted in most international treatment guidelines, intraperitoneal chemotherapy has growing evidence compared with conventional systemic chemotherapy for the treatment of peritoneal carcinomatosis. Cytoreductive surgery with hyperthermic intraperitoneal chemotherapy is well-established for clinical benefit but is technically demanding with substantial treatment-related morbidities and mortality. On the other hand, normothermic intraperitoneal chemotherapy in the form of bidirectional neoadjuvant treatment is promising with various newer chemotherapeutic agents. Regardless of the treatment technique applied, the essential element of success is meticulous patient selection and availability of expertise. Future direction is along the line of personalized treatment with the application of translational science.
\end{abstract}

\section{Keywords}

Gastric Cancer, Peritoneal Carcinomatosis, Hyperthermic Intraperitoneal Chemotherapy (HIPEC), Neoadjuvant Intraperitoneal/Systemic Chemotherapy (NIPS), Cytoreductive Surgery

\footnotetext{
*Corresponding author.
}

How to cite this paper: Lam, K.-O., Law, B.T.-T., Law, S.Y.-K. and Kwong, D.L.-W. (2014) Intraperitoneal Chemotherapy for Gastric Cancer with Peritoneal Carcinomatosis: Is HIPEC the Only Answer? Modern Chemotherapy, 3, 11-19. 


\section{Introduction}

\subsection{Epidemiology}

Gastric cancer is the fifth most common malignancy in the world and almost one million new cases were estimated to have occurred in 2012. About half of the cases occurred in Eastern Asia and a male-predominance was observed [1]. Peritoneal carcinomatosis (PC) is one of the most dismal manifestations of advanced gastric cancer. In more than $20 \%$ of patients, early peritoneal dissemination, in the form of either positive cytology or PC, was detected at presentation [2] and the likelihood increased with the extent of serosal invasion [3]. On the other hand, involvement of the peritoneum as a component of first recurrence was reported to be as high as $10 \%-50 \%$ even after standard D2 lymph node dissection and adjuvant chemotherapy [4]-[6]. Patients with PC not only have a poor quality of life due to various complications including ascites and intestinal obstruction but also have a universally grave prognosis. According to the multicenter prospective EVOCAPE I study, the median overall survival (OS) in gastric cancer patients with PC was 3.1 months substantially worse than the 5.2 months in colorectal cancer patients with PC [7].

\subsection{Staging}

Proper staging workup is essential for assessing the extent of disease and selection of patients for aggressive treatment. Contrast-enhanced CT is regarded as the fundamental imaging modality for PC [8]. The reported sensitivity ranged from $60 \%$ - $90 \%$ depending on the quality of CT, size of the tumor nodules and its location in the peritoneal cavity. The presence of ascites and peritoneal thickening with or without enhancement are the commonest CT features. PET provides complementary staging information to CT with high sensitivity except in signet-ring cell carcinoma which has generally low maximum Standardized Uptake Value [9]. On the other hand, the high physiologic uptake in the stomach, bowel and urinary tract may lead to false-positivity. Diagnostic laparoscopy provides direct visualization of the peritoneal cavity and allows biopsy of lesions. However, it is invasive and may be technically difficult in patients with prior extensive surgery. In addition, it does not allow examination of the retroperitoneal region [8].

The peritoneal cancer index (PCI) is widely-adopted for the staging of PC. The peritoneal cavity is divided into 13 regions and a lesion size score (LS) is given to the largest tumor deposit within each region: LS 0 for no tumor seen, LS 1 for tumor up to $0.5 \mathrm{~cm}$, LS 2 for tumor up to $5 \mathrm{~cm}$ and LS 3 for tumor $>5 \mathrm{~cm}$ or confluence. The PCI is the sum of LS in all regions examined and it ranges from 0 to 39 [10]. Intraoperatively, the completeness of cytoreduction (CC) score is used to assess whether a cytoreductive surgery is complete. CC-0 indicates that there is no residual peritoneal seeding within the operative field and CC- 1 for nodules $<2.5 \mathrm{~cm}$. CC-2 and CC-3 denote residual tumor $2.5-5 \mathrm{~cm}$ and $>5 \mathrm{~cm}$, respectively. CC-0 and CC-1 are regarded as complete cytoreduction. In general, both PCI and CC scores are important prognostic factor for patients with PC [11].

\subsection{Recommendations from Major Treatment Guidelines}

Palliative chemotherapy is recommended for patients with good performance status and adequate organ functions. Platinum-based chemotherapy doublet is favored in the East while chemotherapy triplet with an anthracycline or a taxane is commonly used in the West. For HER2-positive tumors, trastuzumab should be considered [12]. So far, no specific recommendation is given for a different treatment strategy for patients with PC and intraperitoneal chemotherapy is not discussed in any of the treatment guidelines of the National Comprehensive Cancer Network, the European Society for Medical Oncology and the Japanese Gastric Cancer Association [13]-[15]. As such, an appreciable gap exists between clinical practice and best available evidence regarding the optimal treatment of PC. This article serves to review current evidence and explore future directions in the treatment of this distinctive entity.

\section{Intraperitoneal Chemotherapy (IPC) Overview}

Transcoelomic spread of the cancer cells is the principle cause for PC and is independent of the hematological and lymphatic spread in systemic dissemination. Intraperitoneal administration of chemotherapy allows dose intensification since the peritoneal permeabilities of several hydrophilic chemotherapeutic agents are considerably less than the plasma clearance of the same agents [16]. As a result, there is higher drug concentration in the pe- 
ritoneal cavity compared with systemic circulation and produce local cancer cell killing while minimizing systemic toxicity. In a recent metaanalysis that included 2145 patients in twenty prospective randomized controlled trials, surgery and IPC improved 1-, 2- and 3-year mortality rate (Odds Ratio $=0.31,0.27$ and 0.29 , respectively) when compared to surgery alone in advanced gastric cancer [17]. The overall recurrence, peritoneal recurrence and hematogenous metastatic rates were also improved (Odds Ratio $=0.46,0.17$ and 0.63 , respectively) at the price of increasing the morbidity rate (Odd Ratios $=1.82$ ). Although any form of IPC was allowed for inclusion in the metaanalysis, twelve of the twenty studies utilized hyperthermic intraperitoneal chemotherapy (HIPEC) and cisplatin, mitomycin C and 5-FU were the commonly used chemotherapy.

\subsection{Hyperthermic Intraperitoneal Chemotherapy (HIPEC)}

HIPEC combines the dose intensity advantage of IPC and the direct cytotoxic effect of hyperthermia. Patients with PC usually receive HIPEC at a temperature of $40^{\circ} \mathrm{C}-45^{\circ} \mathrm{C}$ over $30-90$ minutes in the operating theatre after cytoreductive surgery. Hyperthermia exhibits a selective cell-killing of malignant cells, potentiates the cytotoxic effect of chemotherapeutic agents and enhances tissue penetration of the agents [18]. It has been used with promising result in PC from various cancers including ovarian, colorectal, peritoneal mesothelioma and pseudomyxoma peritoneii [19]. Among the treatment of PC from gastrointestinal cancers, the result in colorectal cancer was favorable. Verwaal et al. reported the long-term follow-up result of a randomized trial that compared systemic chemotherapy alone with cytoreduction followed by HIPEC and systemic chemotherapy [20]. The median disease-specific survival was significantly improved from 12.6 months in the control arm to 22.2 months in the HIPEC arm ( $=0.028)$. In the subgroup of patients who had a R1 resection, long-term survival is possible with a 5 -year survival rate of $45 \%$. The result in gastric cancer echoes with similar degree of benefit. In a systemic review performed by Gill et al. that included studies of gastric cancer with PC treated by cytoreductive surgery and HIPEC, the median overall survival (OS) was 7.9 months but increased to 15 months in those with CC score 0 or 1 [21]. Overall rate of mortality and morbidity was $4.8 \%$ and $21.5 \%$, respectively. The commonest complications reported were abscess, fistula and anastomotic leak.

Although the morbidity and mortality associated with HIPEC are substantial, studies have shown that the quality of life of patients was comparable to other cancer patients and in general returned to baseline at up to 1 year after treatment despite an initial drop in quality of life [22]-[24]. Nevertheless, the importance of the availability of expertise should not be overemphasized. Kusamura et al. reviewed 462 cases of cytoreductive surgery and HIPEC procedure performed from 1995 to 2012 of the peritoneum surface malignancy program in the Istituto Nazionale dei Turmori in Milan [25]. A steep learning curve was shown and approximately 140 to 150 procedures are required to assure adequate radicality of resection and acceptable safety. Similarly, 80 to 100 cases were necessary to assure short-term prognostic gains in rare peritoneal surface malignancies. Besides expertise, appropriate facilities are also critical. High-voltage electrosurgery is used for dissection, resection and electroevaporation of tumor nodules during cytoreductive surgery and excessive smoke generated from the extensive dissection and lengthy surgery pose potential health hazard. On the other hand, inhalation of chemotherapy aerosols or vapors as well as direct contact with the chemotherapeutic agents are additional health concerns, especially in those who practice open method of HIPEC [26]. Stringent protective measures should be followed to minimize the mentioned hazards.

\subsection{Neoadjuvant Intraperitoneal and Systemic Chemotherapy (NIPS)}

Although HIPEC has encouraging efficacy, the associated morbidity and mortality as well as the demand on expertise and facilities all limit its availability worldwide. Recently, the concept of bidirectional chemotherapy using both intraperitoneal and systemic chemotherapy in the neoadjuvant setting has gained much attention. Taxanes such as paclitaxel and docetaxel are active against gastric cancer. Their remarkably high peritoneal/plasma AUC ratio as a result of the high molecular weight makes them ideal for intraperitoneal administration [27]. Table 1 summarizes studies that used taxanes in NIPS. Yonemura et al. first tested the feasibility of NIPS in 79 gastric cancer patients with PC using oral S-1, intraperitoneal docetaxel and cisplatin [28]. Sixtythree percent of patients had their peritoneal cytology turned negative and $78 \%$ of patient who underwent laparotomy had complete cytoreduction. No treatment-related death was reported. Yonemura et al. subsequently reported the result of the same NIPS regimen in another 96 patients with PC [29]. Patients underwent cytoreductive surgery, gastrectomy and D2 dissection after two cycles of NIPS, the rate of negative cytology and complete 
Table 1. Clinical outcomes of taxane-based NIPS.

\begin{tabular}{|c|c|c|c|c|c|c|}
\hline Author, Year & $\mathrm{N}$ & Chemotherapy & Gastrectomy Rate & MST (Months) & 1-Year Survival & $\begin{array}{l}\text { Most Frequent G3 } \\
\text { Toxicity }\end{array}$ \\
\hline \multicolumn{7}{|c|}{ Paclitaxel } \\
\hline Kitayama, 2014 [32] & 64 & $\begin{array}{c}\text { IP Paclitaxel + } \\
\text { IV Paclitaxel + Oral S-1 }\end{array}$ & $53 \%$ & 26.4 & $82 \%$ & NR \\
\hline Yamguchi, 2013 [33] & 35 & $\begin{array}{c}\text { IP Paclitaxel + } \\
\text { IV Paclitaxel + Oral S-1 }\end{array}$ & $60 \%$ & 17.6 & $77.1 \%$ & 34\% (Neutropenia) \\
\hline Kitayama, 2012 [34] & 100 & $\begin{array}{c}\text { IP Paclitaxel + } \\
\text { IV Paclitaxel + Oral S-1 }\end{array}$ & $52 \%$ & 23.6 & $80 \%$ & 36\% (Neutropenia) \\
\hline $\begin{array}{c}\text { Ishigami, } 2012 \\
\text { [35] }\end{array}$ & 40 & $\begin{array}{c}\text { IP Paclitaxel + } \\
\text { IV Paclitaxel + Oral S-1 }\end{array}$ & NR & 22.5 & $78 \%$ & 38\% (Neutropenia) \\
\hline \multicolumn{7}{|c|}{ Docetaxel } \\
\hline $\begin{array}{c}\text { Canbay, } 2014 \\
{[36]}\end{array}$ & 194 & $\begin{array}{l}\text { IP Docetaxel + } \\
\text { IP Cisplatin + } \\
\text { Oral S-1 followed by } \\
\text { CRS + HIPEC }\end{array}$ & $78 \%$ & 15.8 & $66 \%$ & NR for NIPS \\
\hline $\begin{array}{c}\text { Fushida, } 2014 \\
\text { [37] }\end{array}$ & 39 & $\begin{array}{l}\text { IP Docetaxel + } \\
\text { Oral S-1 }\end{array}$ & $36 \%$ & 16.2 & $70 \%$ & 19\% (Anorexia) \\
\hline Yonemura, 2012 [29] & 96 & $\begin{array}{c}\text { IP Docetaxel + } \\
\text { IP Cisplatin + Oral S-1 }\end{array}$ & $70 \%$ & $\begin{array}{c}14.4 \text { (all) } \\
21.1(\text { CC-0) }\end{array}$ & $61 \%$ (all) & 3.1\% (Fatigue) \\
\hline $\begin{array}{c}\text { Fujiwara, } 2012 \\
{[31]}\end{array}$ & 18 & IP Docetaxel + Oral S-1 & $89 \%$ & 24.6 & $76 \%$ & 6\% (Neutropenia) \\
\hline Yonemura, 2009 [28] & 79 & $\begin{array}{c}\text { IP Docetaxel + } \\
\text { IP Cisplatin + Oral S-1 }\end{array}$ & $38 \%$ & 20.4 (CRS) & $87.4 \%(\mathrm{CRS})$ & $\begin{array}{l}\text { 3.8\% (Derange Renal } \\
\text { Function) }\end{array}$ \\
\hline
\end{tabular}

Abbreviations: IP: Intraperitoneal; IV: Intravenous; NR: Not Reported; CRS: Cytoreductive Surgery; CC: Completeness of Cytoreduction.

pathological response of PC were $69 \%$ and $36.8 \%$, respectively. Fujiwara et al. enrolled 25 treatment-naïve gastric cancer patients with either positive cytology or PC to NIPS that comprised intraperitoneal mitomycin C and cisplatin followed by two cycles of intravenous docetaxel, 5-FU and cisplatin [30]. Radiological response was seen in $59 \%$ of patients while $56 \%$ of patients become negative in peritoneal cytology and the median OS was 16.7 months. In another phase II study by the same study team, 18 patients with positive peritoneal cytology or PC were given two cycles of oral S-1 and intraperitoneal docetaxel [31]. Gastrectomy with lymph node dissection but not peritonectomy was performed for those without gross PC post-NIPS. Peritoneal cytology turned negative in $78 \%$ of cases and $62.5 \%$ of patients with measurable disease showed major response by RECIST criteria. The median OS was 24.6 months and 1-year survival was $76 \%$. Treatment was well-tolerated without grade 4 or above toxicity. In short, NIPS achieves high rate of response and favorable survival outcomes. Results are reproducible and treatment is well-tolerated. Table 2 shows the comparison between HIPEC and NIPS.

\section{Target Therapy}

\subsection{Catumaxomab}

Catumaxomab is the only licensed target therapy for the treatment of malignant ascites so far. It is a trifunctional non-humanized monoclonal antibody with two different antigen-binding sites, one directing at the epithelial tumor cells via the epithelial cell-adhesion molecule (EpCAM) and another directing at the T-cells via CD3 molecule, and a functional Fc domain. The functional Fc domain serves to activate Fc $\gamma$-receptor I-, IIa- and IIIpositive accessory cells. Thus, catumaxomab works as a locoregional immunotherapy against EpCAM+ tumor cells in the peritoneal cavity [38]. In the landmark phase II/III trial that randomized cancer patients with recurrent symptomatic malignant ascites who were resistant to conventional chemotherapy into paracentesis or paracentesis with intraperitoneal infusion of catumaxomab, the puncture-free survival was significantly increased with catumaxomab (46 days vs 11 days, HR 0.254; p < 0.0001) [39]. The most common catumaxomab-related adverse events were cytokine release-related symptoms (pyrexia, nausea and vomiting) and abdominal pain which were largely mild to moderate and reversible. In addition, treatment with catumaxomab was shown to de- 
Table 2. Comparison between HIPEC and NIPS.

\begin{tabular}{ccc}
\hline & HIPEC & NIPS \\
\hline Timing & Intraoperative & Neoadjuvant \\
Intraperitoneal Chemotherapy & $\begin{array}{c}\text { Cisplatin or Mitomycin-C or Oxaliplatin } \\
\text { or Doxorubicin } \\
\text { Intraabdominal Temperature }\end{array}$ & Paclitaxel or Docetaxel \\
Systemic Chemotherapy & $40^{\circ} \mathrm{C}-45^{\circ} \mathrm{C}$ & Body Temperature \\
Morbidity & Yes or No & Yes \\
Mortality & High-Intermediate & Intermediate \\
Expertise & Yes & No \\
Efficacy & High & Low \\
Level of Evidence & High & High \\
Capital Investment & Intermediate & Low \\
Health hazard & High & Low \\
\hline
\end{tabular}

lay deterioration in quality of life [40]. To date, catumaxomab was studied in the adjuvant treatment of patient with completely resected gastric cancer with serosa infiltration (NCT00352833) and in those who have received neoadjuvant chemotherapy (NCT00464893). Both studies have been completed and the results are awaited. There are ongoing studies to evaluate the combination of catumaxomab with complete cytoreduction in the palliative setting (NCT01784900) and the combination catumaxomab with systemic chemotherapy in the induction setting (NCT01504256) for patients with PC from gastric cancer. The result of these studies will expand the indications of catumaxomab in gastric cancer.

\subsection{Trastuzumab}

Trastuzumab is a humanized monoclonal antibody against human epidermal growth factor receptor 2 (HER2). In the TOGA study, trastuzumab in addition to chemotherapy significantly improved the OS of patients with HER2positive advanced gastric or gastro-oesophageal junction cancer [12]. Bozzetti et al. has shown that there is high concordance rate of HER2 status around 95\% - 98\% between the primary gastric tumor and the metastases [41]. Thus, intraperitoneal administration of trastuzumab to augment the treatment efficacy will be a logical assumption. So far, there is only one case report on the use of intraperitoneal trastuzumab [42]. A phase I dose-escalating study is ongoing on the intraperitoneal use of radiolabelled trastuzumab in HER2 expressing tumors with predominantly intra-abdominal disease (NCT01384253).

\subsection{Bevacizumab}

Bevacizumab is a humanized monoclonal antibody against vascular endothelial growth factor (VEGF). VEGF is responsible for angiogenesis and vascular permeability which in turn enhance PC and its associated ascites. Preclinical model has shown that bevacizumab might be effective for treatment of PC from gastric cancer [43]. El-Shami et al. has reported the efficacy of a cohort of nine patients with refractory ascites due to various solid tumors who were treated by intraperitoneal bevacizumab [44]. However, there is no ongoing study of its use in patients with gastric cancer.

Current studies on intraperitoneal chemotherapy for gastric cancer are shown in Table 3.

\section{Conclusion}

The treatment of gastric cancer with PC is evolving and the use of intraperitoneal chemotherapy has improved the outcomes of this group of patients. While HIPEC benefits a selected group of patients in the presence of expertise, NIPS offers less technically demanding alternatives with lower morbidity and mortality. Catumaxomab is just the beginning of personalized medicine in the treatment of PC and more translational studies have 
Table 3. Current clinical trials of intraperitoneal chemotherapy.

\begin{tabular}{|c|c|c|c|c|c|c|}
\hline & Phase & Primary endpoint & $\begin{array}{l}\text { Major eligibility } \\
\text { criteria }\end{array}$ & $\begin{array}{l}\text { Chemotherapy } \\
\text { (intraperitoneal) }\end{array}$ & $\begin{array}{l}\text { Chemotherapy } \\
\text { (systemic) }\end{array}$ & Status \\
\hline \multicolumn{7}{|c|}{ Adjuvant } \\
\hline NCT00992199 & II & $\begin{array}{l}\text { Rate of peritoneal } \\
\text { metastasis }\end{array}$ & T3-4NxM0 & Cisplatin and 5FU & Not specified & Unknown \\
\hline NCT00858338 & II & Toxicity & IB-IVM0 & Floxuridine & $\begin{array}{l}\text { 5-FU and concurrent } \\
\text { radiotherapy }\end{array}$ & Completed \\
\hline NCT00006038 & II & $\begin{array}{l}\text { Efficacy and } \\
\text { toxicity }\end{array}$ & $\begin{array}{l}\text { T2N1-2M0 or } \\
\text { T3-4NanyM0 }\end{array}$ & $\begin{array}{l}\text { Floxuridine and } \\
\text { leucovorin }\end{array}$ & $\begin{array}{l}\text { Docetaxel, cisplatin } \\
\text { and 5-FU }\end{array}$ & Completed \\
\hline NCT00002783 & II & $\begin{array}{l}\text { Efficacy and } \\
\text { toxicity }\end{array}$ & II-IVM0 & $\begin{array}{l}\text { Floxuridine and } \\
\text { leucovorin }\end{array}$ & Cisplatin and 5-FU & Completed \\
\hline NCT00004103 & II & RR and TTF & IB-IVM0 & Floxuridine and cisplatin & Cisplatin and irinotecan & Completed \\
\hline NCT01683864 & II/III & PC free survival & $\begin{array}{l}\text { T2-4Nany and } \\
\text { Pcyt+ }\end{array}$ & $\begin{array}{l}\text { MMC and cisplatin } \\
\text { (hyperthermic) }\end{array}$ & No & Recruiting \\
\hline NCT02205008 & III & RFS & $\begin{array}{l}\text { Suspicious of } \\
\text { serosal invasion }\end{array}$ & MMC and 5-FU & S-1 & Recruiting \\
\hline NCT01882933 & III & OS & $\mathrm{T} 3 / 4, \mathrm{~N}+$ or Pcyt + & $\begin{array}{c}\text { Oxaliplatin } \\
\text { (hyperthermic) }\end{array}$ & No & Recruiting \\
\hline \multicolumn{7}{|c|}{ Palliative } \\
\hline NCT02024841 & I & MTD and RD & $\begin{array}{c}\text { Primary gastric } \\
\text { cancer + PC or } \\
\text { Pcyt+ }+\end{array}$ & Docetaxel & Cisplatin and S-1 & Recruiting \\
\hline NCT01525771 & $\mathrm{I} / \mathrm{II}$ & $\begin{array}{c}\text { MTD in phase I; } \\
\text { PFS at 6months in } \\
\text { phase II }\end{array}$ & PC or Pcyt+ & Docetaxel & $\begin{array}{l}\text { Cisplatin and capecita- } \\
\text { bine }\end{array}$ & Ongoing \\
\hline NCT01379482 & II & OS & $\begin{array}{l}\text { Primary gastric } \\
\text { cancer + PC }\end{array}$ & $\begin{array}{l}\text { Cisplatin and doxorubicin } \\
\text { (Hyperthermic) }\end{array}$ & FP-based & Completed \\
\hline NCT01854255 & II & CBR & $\mathrm{PC}$ & $\begin{array}{l}\text { Cisplatin and doxorubicin } \\
\text { (pressurized aerosal) }\end{array}$ & No & Recruiting \\
\hline NCT02092298 & II & OS & PC or Pcyt+ & $\begin{array}{l}\text { MMC, cisplatin and } \\
\text { sodium thiosulfate }\end{array}$ & No & Recruiting \\
\hline NCT01739894 & II & OS & PC or Pcyt+ & Paclitaxel & $\begin{array}{l}\text { Oxaliplatin and } \\
\text { capecitabine }\end{array}$ & Recruiting \\
\hline NCT01471132 & II & OS & PC or Pcyt+ & $\begin{array}{l}\text { Oxaliplatin and paclitaxel } \\
\text { (hyperthermic) }\end{array}$ & No & Recruiting \\
\hline NCT01342653 & II & DFS & PC & $\begin{array}{l}\text { Docetaxel and cisplatin } \\
\text { MMC and doxorubicin } \\
\text { (hyperthermic) }\end{array}$ & $\begin{array}{l}\text { 5-FU, docetaxel and } \\
\text { cisplatin }\end{array}$ & Recruiting \\
\hline NCT01784900 & II & PFS & PC and CCR & Catumaxomab & No & Recruiting \\
\hline NCT01504256 & II & $\begin{array}{c}\text { Rate of mCR of } \\
\text { PC }\end{array}$ & PC & Catumaxomab & $\begin{array}{l}\text { 5-FU, oxaliplatin and } \\
\text { docetaxel }\end{array}$ & Recruiting \\
\hline NCT02158988 & III & OS & PC & $\begin{array}{l}\text { MMC and cisplatin } \\
\text { (hyperthermic) }\end{array}$ & $\begin{array}{l}\text { Epirubicin, oxaliplatin } \\
\text { and capecitabine }+/- \\
\text { trastuzumab }\end{array}$ & Recruiting \\
\hline
\end{tabular}

Abbreviations: 5-FU: 5-Fluorouracil; RR: Response Rate; TTF: Time to Treatment Failure; PC: Peritoneal Carcinomatosis; Pcyt+: Peritoneal cytology positive; MMC: Mitomycin C; MTD: Maximum Tolerated Dose; RD: Recommended Dose; PFS: Progression Free Survival; OS: Overall Survival; FP: Fluoropyrimidine; CBR: Clinical Benefit Rate; DFS: Disease Free Survival; CCR: Complete Cytoreduction; mCR: Macroscopic Complete Response.

to be done in deciphering the biology of this distinct disease entity. Ongoing studies that apply novel agents, techniques and concept will add on to the armamentarium against PC.

\section{References}

[1] WHO (2012) All Cancers (Excluding Non-Melanoma Skin Cancer) Estimated Incidence, Mortality and Prevalence 
Worldwide in 2012. WHO, Geneva. http://globocan.iarc.fr/Pages/fact_sheets_cancer.aspx

[2] Mezhir, J.J., Shah, M.A., Jacks, L.M., Brennan, M.F., Coit, D.G. and Strong, V.E. (2010) Positive Peritoneal Cytology in Patients with Gastric Cancer: Natural History and Outcome of 291 Patients. Annals of Surgical Oncology, 17, 3173-3180. http://dx.doi.org/10.1245/s10434-010-1183-0

[3] Ikeguchi, M., Oka, A., Tsujitani, S., Maeta, M. and Kaibara, N. (1994) Relationship between Area of Serosal Invasion and Intraperitoneal Free Cancer Cells in Patients with Gastric Cancer. Anticancer Research, 14, 2131-2134.

[4] D’Angelica, M, Gonen, M., Brennan, M.F., Turnbull, A.D., Bains, M. and Karpeh, M.S. (2004) Patterns of Initial Recurrence in Completely Resected Gastric Adenocarcinoma. Annals of Surgery, 240, 808-816. http://dx.doi.org/10.1097/01.sla.0000143245.28656.15

[5] Bang, Y.J., Kim, Y.W., Yang, H.K., Chung, H.C., Park, Y.K., Lee, K.H., et al. (2012) Adjuvant Capecitabine and Oxaliplatin for Gastric Cancer After D2 Gastrectomy (CLASSIC): A Phase 3 Open-Label, Randomized Controlled Trial. Lancet, 379, 315-321. http://dx.doi.org/10.1016/S0140-6736(11)61873-4

[6] Sasako, M., Sakuramoto, S., Katai, H., Kinoshita, T., Furukawa, H., Yamaguchi, T., et al. (2011) Five-Year Outcomes of a Randomized Phase III Trial Comparing Adjuvant Chemotherapy with S-1 versus Surgery Alone in Stage II or III Gastric Cancer. Journal of Clinical Oncology, 29, 4387-4393. http://dx.doi.org/10.1200/JCO.2011.36.5908

[7] Sadeghi, B., Arvieux, C., Glehen, O., Beaujard, A.C., Rivoire, M., Baulieux, J., et al. (2000) Peritoneal Carcinomatosis from Non-Gynaecologic Malignancies: Results of the EVOCAPE 1 Multicentric Prospective Study. Cancer, 88, 358363. http://dx.doi.org/10.1002/(SICI)1097-0142(20000115)88:2<358::AID-CNCR16>3.0.CO;2-O

[8] Yan, T.D., Morris, D.L., Shigeki, K., Dario, B. and Marcello, D. (2008) Preoperative Investigations in the Management of Peritoneal Surface Malignancy with Cytoreductive Surgery and Perioperative Intraperitoneal Chemotherapy: Expert Consensus Statement. Journal of Surgical Oncology, 98, 224-227. http://dx.doi.org/10.1002/jso.21069

[9] Alakus, H., Batur, M., Schmidt, M., Drebber, U., Baldus, S.E., Vallbohmer, D., et al. (2010) Variable 18F-Fluorodeoxyglucose Uptake in Gastric Cancer Is Associated with Different Levels of GLUT-1 Expression. Nuclear Medicine Communications, 31, 532-538.

[10] Jacquet, P. and Sugarbaker, P.H. (1996) Clincial Research Methodologies in Diagnosis and Staging of Patients with Peritoneal Carcinomatosis. Cancer Research and Treatment, 83, 359-374. http://dx.doi.org/10.1007/978-1-4613-1247-5_23

[11] Harmon, R.L. and Sugarbaker, P.H. (2005) Prognostic Indicators in Peritoneal Carcinomatosis from Gastrointestinal Cancer. International Seminars in Surgical Oncology, 2, 3. http://dx.doi.org/10.1186/1477-7800-2-3

[12] Bang, Y.J., Van Cutsem, E., Feyereislova, A., Chung, H.C., Shen, L., Sawaki, A., et al. (2010) Trastuzumab in Combination with Chemotherapy versus Chemotherapy Alone for Treatment of HER2-Positive Advanced Gastric or Gastro-Oesophageal Junction Cancer (TOGA): A Phase 3, Open-Label, Randomized Controlled Trial. The Lancet, 376, 687-697. http://dx.doi.org/10.1016/S0140-6736(10)61121-X

[13] National Comprehensive Cancer Network Clinical Practice Guideline in Oncology. Gastric Cancer, Version 1.2014. http://www.nccn.org/professionals/physician_gls/pdf/gastric.pdf

[14] Waddell, T., Verheij, M., Allum, W., Cunningham, D., Cervantes, A. and Arnold, D., European Society for Medical Oncology (ESMO), European Society of Surgical Oncology (ESSO), European Society of Radiotherapy and Oncology (ESTRO) (2013) Gastric Cancer: ESMO-ESSO-ESTRO Clinical Practice Guidelines for Diagnosis, Treatment and Follow-Up. Annals of Oncology, 24, vi57-vi63. http://dx.doi.org/10.1093/annonc/mdt344

[15] Japanese Gastric Cancer Association (2011) Japanese Gastric Cancer Treatment Guidelines 2010 (ver. 3). Gastric Cancer, 14, 113-123. http://dx.doi.org/10.1007/s10120-011-0042-4

[16] Dedrick, R.L., Myers, C.E., Bungay, P.M. and De Vita Jr., V.T. (1978) Pharmacokinetic Rationale for Peritoneal Drug Administration in the Treatment of Ovarian Cancer. Cancer Treatment Reports, 62, 1-11.

[17] Coccolini, F., Cotte, E., Glehen, O., Lotti, M., Poiasina, E., Catena, F., et al. (2014) Intraperitoneal Chemotherapy in Advanced Gastric Cancer. Meta-Analysis of Randomized Trials. European Journal of Surgical Oncology, 40, 12-26. http://dx.doi.org/10.1016/j.ejso.2013.10.019

[18] Sticca, R.P. and Dach, B.W. (2003) Rationale for Hyperthermia with Intraoperative Intraperitoneal Chemotherapy Agents. Surgical Oncology Clinics of North America, 12, 689-701. http://dx.doi.org/10.1016/S1055-3207(03)00029-2

[19] Kitayama, J. (2014) Intraperitoneal Chemotherapy against Peritoneal Carcinomatosis. Current Status and Future Perspective. Surgical Oncology, 23, 99-106. http://dx.doi.org/10.1016/j.suronc.2014.03.004

[20] Verwaal, V.J., Bruin, S., Boot, H., van Slooten, G. and van Tinteren, H. (2008) 8-Year Follow-Up of Randomized Trial: Cytoreduction and Hyperthermic Intraperitoneal Chemotherapy versus Systemic Chemotherapy in Patients with Peritoneal Carcinomatosis of Colorectal Cancer. Annals of Surgical Oncology, 15, 2426-2432. http://dx.doi.org/10.1245/s10434-008-9966-2

[21] Gill, R.S., Al-Adra, D.P., Nagendran, J., Campbell, S., Shi, X., Haase, E. and Schiller, D. (2011) Treatment of Gastric 
Cancer with Peritoneal Carcinomatosis by Cytoreductive Surgery and HIPEC: A Systematic Review of Survival, Mortality, and Morbidity. Journal of Surgical Oncology, 104, 692-698. http://dx.doi.org/10.1002/jso.22017

[22] Chia, C.S., Tan, W.J., Wong, J.F., Tan, G.H., Lim, C., Wang, W., et al. (2014) Quality of Life in Patients with Peritoneal Surface Malignancies after Cytoreductive Surgery and Hyperthermic Intraperitoneal Chemotherapy. European Journal of Surgical Oncology, 40, 909-916. http://dx.doi.org/10.1016/j.ejso.2013.12.028

[23] Tan, W.J., Wong, J.F., Chia, C.S., Tan, G.H., Soo, K.C. and Teo, M.C. (2013) Quality of Life after Cytoreductive Surgery and Hyperthermic Intraperitoneal Chemotherapy: An Asian Perspective. Annals of Surgical Oncology, 20, 42194223. http://dx.doi.org/10.1245/s10434-013-3133-0

[24] Zhu, Y., Hanna, N., Boutros, C. and Alexander Jr., H.R. (2012) Assessment of Clinical Benefit and Quality of Life in Patients Undergoing Cytoreduction and Hyperthermic Intraperitoneal Chemotherapy (HIPEC) for Management of Peritoneal Metastases. Journal of Gastrointestinal Oncology, 4, 62-71. http://dx.doi.org/10.3978/j.issn.2078-6891.2012.053

[25] Kusamura, S., Baratti, D., Hutanu, I., Rossi, P. and Deraco, M. (2012) The Importance of The Learning Curve and Surveillance of Surgical Performance in Peritoneal Surface Malignancy Programs. Surgical Oncology Clinics of North America, 21, 559-576. http://dx.doi.org/10.1016/j.soc.2012.07.011

[26] González-Moreno, S., González-Bayón, L. and Ortega-Pérez, G. (2012) Hyperthermic Intraperitoneal Chemotherapy: Methodology and Safety Considerations. Surgical Oncology Clinics of North America, 21, 543-557. http://dx.doi.org/10.1016/j.soc.2012.07.001

[27] Sugarbaker, P.H., Mora, J.T., Carmignani, P., Stuart, O.A. and Yoo, D. (2005) Update on Chemotherapeutic Agents Utilized for Perioperative Intraperitoneal Chemotherapy. The Oncologist, 10, 112-122. http://dx.doi.org/10.1634/theoncologist.10-2-112

[28] Yonemura, Y., Endou, Y., Shinbo, M., Sasaki, T., Hirano, M., Mizumoto, A., et al. (2009) Safety and Efficacy of Bidirectional Chemotherapy for Treatment of Patients with Peritoneal Dissemination from Gastric Cancer: Selection for Cytoreductive Surgery. Journal of Surgical Oncology, 100, 311-316. http://dx.doi.org/10.1002/jso.21324

[29] Yonemura, Y., Elnemr, A., Endou, Y., Ishibashi, H., Mizumoto, A., Miura, M., et al. (2012) Effects of Neoadjuvant Intraperitoneal/Systemic Chemotherapy (Bidirectional Chemotherapy) for the Treatment of Patients with Peritoneal Metastasis from Gastric Cancer. International Journal of Surgical Oncology, 2012, 1-8. http://dx.doi.org/10.1155/2012/148420

[30] Fujiwara, Y., Takiguchi, S., Nakajima, K., Miyata, H., Yamasaki, M., Kurokawa, Y., et al. (2011) Neoadjuvant Intraperitoneal and Systemic Chemotherapy for Gastric Cancer Patients with Peritoneal Dissemination. Annals of Surgical Oncology, 18, 3726-3731. http://dx.doi.org/10.1245/s10434-011-1770-8

[31] Fujiwara, Y., Takiquchi, S., Nakajima, K., Miyata, H., Yamasaki, M., Kurokawa, Y., et al. (2012) Intraperitoneal Docetaxel Combined with S-1 for Advanced Gastric Cancer with Peritoneal Dissemination. Journal of Surgical Oncology, 105, 38-42. http://dx.doi.org/10.1002/jso.22057

[32] Kitayama, J., Ishigami, H., Yamaguchi, H., Yamashita, H., Emoto, S., Kaisaki, S., et al. (2014) Salvage Gastrectomy after Intravenous and Intraperitoneal Paclitaxel (PTX) Administration with Oral S-1 for Peritoneal Dissemination of Advanced Gastric Cancer with Malignant Ascites. Annals of Surgical Oncology, 21, 539-546. http://dx.doi.org/10.1245/s10434-013-3208-y

[33] Yamaguchi, H., Kitayama, J., Ishigami, H., Emoto, S., Yamashita, H. and Watanabe, T. (2013) A Phase 2 Trial of Intravenous and Intraperitoneal Paclitaxel Combined Eith S-1 for Treatment of Gastric Cancer with Macroscopic Peritoneal Metastasis. Cancer, 119, 3354-3358. http://dx.doi.org/10.1002/cncr.28204

[34] Kitayama, J., Ishigami, H., Yamaguchi, H., Yamashita, H., Emoto, S. and Kaisaki, S. (2012) S-1 Plus Intravenous and Intraperitoneal Paclitaxel for Gastric Cancer with Peritoneal Metastasis. Gastrointestinal Cancer Research, 5, S10-S13.

[35] Ishigami, H., Kitayama, J., Kaisaki, S., Hidemura, A., Kato, M., Otani, K., et al. (2010) Phase II Study of Weekly Intravenous and Intraperitoneal Paclitaxel Combined with S-1 for Advanced Gastric Cancer with Peritoneal Metastasis. Annals of Oncology, 21, 67-70. http://dx.doi.org/10.1093/annonc/mdp260

[36] Canbay, E., Mizumoto, A., Ichinose, M., Ishibashi, H., Sako, S., Hirano, M., et al. (2014) Outcome Data Of Patients with Peritoneal Carcinomatosis from Gastric Origin Treated by a Strategy of Bidirectional Chemotherapy Prior to Cytoreductive Surgery and Hyperthermic Intraperitoneal Chemotherapy in a Single Specialized Center in Japan. Annals of Surgical Oncology, 21, 1147-1152. http://dx.doi.org/10.1245/s10434-013-3443-2

[37] Fushida, S., Kinoshita, J., Kaji, M., Hirono, Y., Goda, F., Yagi, Y., et al. (2013) Phase I/II Study of Intraperitoneal Docetaxel Plus S-1 for the Gastric Cancer Patients with Peritoneal Carcinomatosis. Cancer Chemotherapy and Pharmacology, 71, 1265-1272. http://dx.doi.org/10.1007/s00280-013-2122-0

[38] Jäger, M., Schoberth, A., Ruf, P., Hess, J., Hennig, M., Schmalfeldt, B., et al. (2012) Immunomonitoring Results of a Phase II/III Study of Malignant Ascites Patients Treated with the Trifunctional Antibody Catumaxomab (Anti-Epcam 
X Anti-CD3). Cancer Research, 72, 24-32. http://dx.doi.org/10.1158/0008-5472.CAN-11-2235

[39] Heiss, M.M., Murawa, P., Koralewski, P., Kutarska, E., Kolesnik, O.O., Ivanchenko, V.V., et al. (2010) The Trifunctional Antibody Catumaxomab for the Treatment of Malignant Ascites Due to Epithelial Cancer: Results of a Prospective Randomized Phase II/III Trial. International Journal of Cancer, 127, 2209-2221.

http://dx.doi.org/10.1002/ijc.25423

[40] Wimberger, P., Gilet, H., Gonschior, A.K., Heiss, M.M., Moehler, M., Oskay-Oezcelik, G., et al. (2012) Deterioration in Quality Of Life (Qol) In Patients with Malignant Ascites: Results from a Phase II/III Study Comparing Paracentesis plus Catumaxomab with Paracentesis Alone. Annals of Oncology, 23, 1979-1985. http://dx.doi.org/10.1093/annonc/mds178

[41] Bozzetti, C., Negri, F.V., Lagrasta, C.A., Crafa, P., Bassano, C., Tamagnini, I., et al. (2011) Comparison of HER2 Status in Primary and Paired Metastatic Sites of Gastric Carcinoma. British Journal of Cancer, 104, 1372-1376. http://dx.doi.org/10.1038/bjc.2011.121

[42] Berretta, M., Fisichella, R., Borsatti, E., Lleshi, A., Ioffredo, S., Meneguzzo, N., et al. (2014) Feasibility of Intraperitoneal Trastuzumab Treatment in a Patient with Peritoneal Carcinomatosis from Gastric Cancer. European Review for Medical and Pharmacological Sciences, 18, 689-692.

[43] Yagi, Y., Fushida, S., Harada, S., Tsukada, T., Kinoshita, J., Oyama, K., et al. (2009) Biodistribution of Humanized Anti-VEGF Monoclonal Antibody/Bevacizumab on Peritoneal Metastatic Models with Subcutaneous Xenograft of Gastric Cancer in Mice. Cancer Chemotherapy and Pharmacology, 66, 745-753. http://dx.doi.org/10.1007/s00280-009-1219-y

[44] El-Shami, K., Elsaid, A. and El-Kerm, Y. (2007) Open-Label Safety and Efficacy Pilot Trial of Intraperitoneal Bevacizumab as Palliative Treatment in Refractory Malignant Ascites. Journal of Clinical Oncology, 25, 9043. 
Scientific Research Publishing (SCIRP) is one of the largest Open Access journal publishers. It is currently publishing more than 200 open access, online, peer-reviewed journals covering a wide range of academic disciplines. SCIRP serves the worldwide academic communities and contributes to the progress and application of science with its publication.

Other selected journals from SCIRP are listed as below. Submit your manuscript to us via either submit@scirp.org or Online Submission Portal.
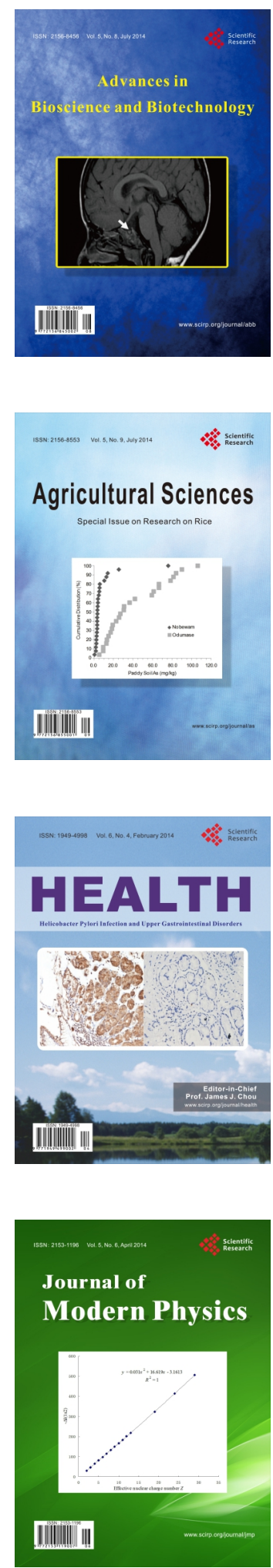
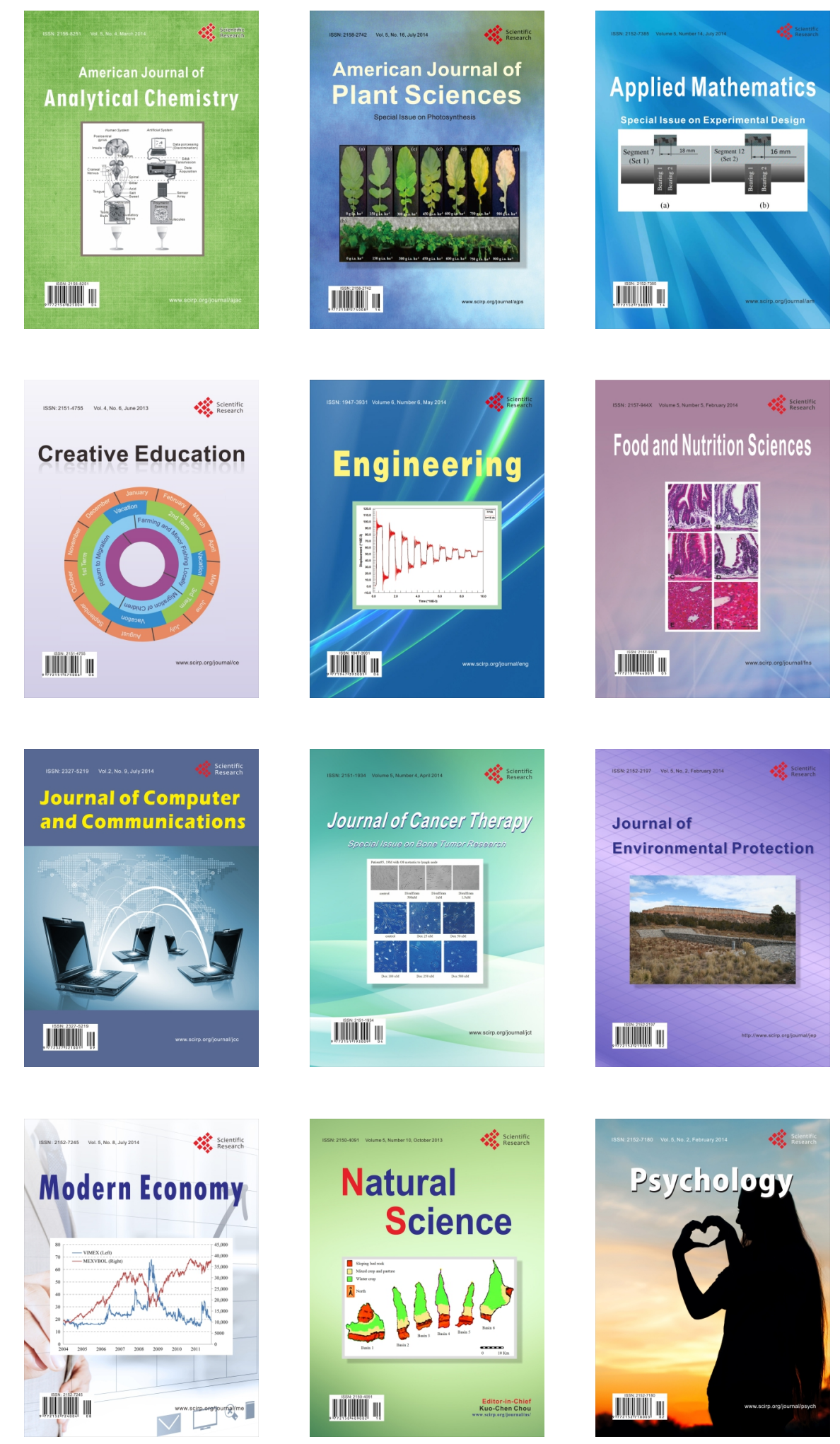